\title{
LA RELACIÓN ENTRE DERECHO PENAL Y POLÍTICA: MÉTODO DEMOCRÁTICO Y MÉTODO CIENTÍFICO***
}

Prof. Massimo Donini*

\begin{abstract}
SUMARIO: 0.0. Premisa. El método de la ciencia y sus vicios de origen: normativismo integral y nacionalismo. 1.0. Por qué la ciencia penal tiene una relación atormentada y neurótica con la política. 2.0. Las razones históricas y filosóficas de la autonomía científica del derecho (penal) del siglo XIX con respecto a política. La "crisis" de las principales razones apuntadas. 3.0. El "método de la ciencia" y el "método de la democracia" frente a la política judicial en materia penal en conexión con la (más tradicional) concepción del derecho como ciencia hermenéutica e "individualizadora". La imposible supresión de la convivencia entre los modelos neopositivistas y hermenéuticos de ciencia. 4.0. La extensión del "paradigma aristocrático" también al ámbito judicial. Empirismo y valores en el método del Tribunal Constitucional. El derecho penal como teología civil o como ciencia social. 5.0. La "política" que cultivan los científicos: el idealismo de la así denominada ciencia "funcionalista" o bien orientada en sentido "político-criminal", u orientada "a las consecuencias", pero no empíricamente. 6.0. El juego de los roles: ciencia académica y judicatura (en Italia) frente al legislador: "Die Reform sind wir"? 7.0. La dimensión internacional de los principios y la necesidad de que la comparación se convierta en "método de la dogmática" y no sea sólo una disciplina autónoma cuyos objetivos sean meramente cognoscitivos. Comparación y trabajo de équipe. 8.0. La dimensión política y "crítica" de los principios y la necesaria democratización de la ciencia. De la auctoritas institucional a la autoridad basada en un conocimiento verificable. Empirismo y método penal.
\end{abstract}

\subsection{Premisa. El método de la ciencia y sus vicios de origen: normativismo integral y nacionalismo.}

Antepongo al hecho de ser un penalista "europeo", que no me olvidaré de ser un penalista italiano. No presentaré como verdades universales las características de la ciencia penal italiana y, por tanto, buscaré una koinè, y no la mera exportación de lo 'nuestro'.

El primer vicio de origen del método tradicional de la ciencia jurídica (e igualmente de la ciencia penal) es el normativismo integral, la reducción del derecho a mera norma, aunque sea, en última instancia, la norma constitucional. Partiendo de esta crítica, tendré que pronunciarme seguidamente contra el derecho (objeto de la ciencia penal) como mera norma (tecnicismo jurídico extremo) y, al mismo tiempo, contra el derecho (objeto de la ciencia penal) como derecho constituido únicamente por principios constitucionales (constitucionalismo extremo).

\footnotetext{
* Traducción: Cristina Méndez Rodríguez, Profesora Titular de Derecho Penal. Universidad de Salamanca.

** En este trabajo se anticipan algunos temas que son objeto de una monografía que está siendo ultimada por el autor con el título Democrazia penale. L'impatto del pluralismo su una cultura aristocratica. Constituye también la intervención que presentó el autor en el coloquio que se desarrolló en Toledo en los días 13-15 de abril de 2000 con el título "Crítica y justificación del Derecho penal en el cambio de siglo. El análisis crítico de la escuela de Francfort", y en esta medida, su composición y referencias bibliográficas representan un homenaje a la «Escuela de Francfort»

* Catedrático de Derecho Penal de la Universidad de Modena e Reggio Emilia.
} 
Considerando al derecho, unitariamente, como norma, decisión e institución ${ }^{1}$, podemos decir que el objeto de la ciencia penal es doble²:

a) el derecho penal (como norma, decisión e institución);

b) el objeto del derecho penal: la criminalidad y las distintas materias a que ésta se refiere (ámbitos de regulación: bienes jurídicos y sus estatutos jurídicos; por ejemplo, Estado, administración pública, derechos del hombre, economía, empresa, banca, circulación vial, ambiente, etc.).

Por tanto, advertimos objetos de primer y segundo grado.

El primero de ellos, indicado en el apartado a) se descompone a su vez en tres dimensiones. El predominio del punto de vista normativo (el derecho como norma), implica y no excluye la entrada de información procedente de las decisiones jurídicas (sentencias) que aplican y 'hacen' derecho, y del papel y de la función institucional de quien lo aplica; este predominio implica además, e igualmente no excluye, la información que procede del estudio (criminológico, sociológico, económico, político, etc.) de las materias que son objeto de regulación y de la criminalidad.

Este modelo explicativo del derecho penal como ciencia, aunque sea muy avanzado, presenta, sin embargo, un déficit: la acientificidad del conocimiento del objeto del derecho penal tal y como se refleja en las decisiones del legislador (que demasiado a menudo, ignora o desprecia a la criminología y a las ciencias empíricas) ${ }^{3}$. En la medida en que la ley no nace como un programa verificado o, al menos, racional, de control social respecto a los fenómenos que querría y en realidad no sabe regular, se deriva, consecuentemente, la dificultad de dar entrada a enfoques que se orienten a las consecuencias en clave hermenéutica. Y ello porque el propio programa condicional (la norma abstracta) no tiene una base científica adecuada: si el Parlamento no tiene en cuenta a la criminología o a las ciencias sociales para construir los tipos penales, si éstos no tienen una adecuada matriz teleológica, ¿por qué, o con qué límites se les debería dar un margen en sede interpretativa o ejecutiva? $\dot{ } \mathrm{O}$ tendríamos que pensar en nuevas finalidades que el intérprete (doctrina, jurisprudencia) aplicaría ab extra a normas nacidas ciegas? Este déficit explica el éxito permanente de posturas idealistas (aunque estén enmascaradas de teleologismo, funcionalismo o valoraciones pseudo político-criminales), que no miden las consecuencias de las decisiones criminalizadoras: basta que las incriminaciones y las condenas satisfagan el consenso social que "da estabilidad" al sentimiento de seguridad colectiva, reintegrando idealmente el orden jurídico violado y la fidelidad al ordenamiento.

En efecto, la praxis legislativa, ignorante del saber empírico-criminológico, y la tradicional ciencia normativa penal, igualmente ignorante del saber criminológico (cfr. los principales "Manuales" de derecho penal) confirman conjuntamente la 'lógica' coherencia de este matrimonio. Hay que destacar que incluso aquéllos que proclaman la necesidad del saber criminológico, cuando escriben de teoría del delito, de parte general e incluso de tipos penales concretos, omiten completamente cualquier referencia al saber criminológico

\footnotetext{
${ }^{1}$ Cfr. DONINI, Dogmatica penale e politica criminale a orientamento costituzionalistico. Conoscenza e controllo critico delle scelte di criminalizzazione, en Dei delitti e delle pene, ESI, Nápoles, n. 3/1998, 37 ss, 43 ss.

2 Cfr. para reflexiones convergentes sobre la "apertura" a las ciencias sociales, sobre la "criminalidad" como objeto de la ciencia penal (y no sólo de la criminología), HASSEMER, Nomos Kommentar zum StGB, Nomos Verlag, Baden-Baden,1995, Vor $\$ 1 / 1$ ss.

${ }_{3}^{3}$ Cfr. DONINI, voz Teoria del reato, en Digesto Disc.Pen., vol. XIV, Utet, Turín, 1999, 237.
} 
(salvo excepciones). No se sabe como administrarlo: cuando se critica el derecho vigente, o cuando se habla... de criminología se dice que ésta (y las ciencias sociales) son necesarias, pero no se hace lo mismo cuando se entra in medias res en el derecho penal para comentarlo o sistematizarlo ${ }^{4}$.

El segundo vicio de origen, junto al normativismo integral (conforme a la cultura iuspositivista) es el provincianismo nacionalista: una "ciencia nacional". Que el derecho sea nacional no significa que su estudio sea "científico" si es de carácter nacionalista. Bajo este aspecto, el ejemplo negativo de la ciencia penal de países fuertes como los de common law, Alemania y Francia, está en la mente de todos. Hoy en día es igualmente evidente que la internacionalización progresiva del derecho (también del derecho penal) contradice las raíces de una ciencia penal marcadamente nacionalista.

\subsection{Por qué la ciencia penal tiene una relación atormentada y neurótica con la política.}

Las carencias históricas del método del legislador (irracional, desconocedor del empirismo, a la búsqueda del consenso social y electoral, aproximativo, etc.) condicionan el método del estudioso del derecho y comprometen, desde su origen, su relación fisiológica y positiva con la política, excepto en los casos en los que la ley ha recibido las sugerencias de los estudiosos (como sucedió, por ejemplo, en Italia con el Código Rocco de 1930, o, en más ocasiones aún, en Alemania - no hoy en día, sino - después de la "Vergleichende Darstellung", con las reformas de los años 1968/75).

Además, la ciencia penal tiene una relación atormentada con la política porque ninguna rama del derecho tiene tanto que ver con la irracionalidad como el derecho penal: el derecho penal disciplina comportamientos irracionales y previene reacciones irracionales ${ }^{5}$.

Se trata de conductas sólo en parte reconducibles a una rational choice, a un rationale Verbrecher. De aquí se deduce que la irracionalidad de las ofensas y de las posibles reacciones privadas condiciona la racionalidad de las respuestas. El derecho penal es un continuo intento de racionalizar la necesidad de defensa-venganza. La política, por el contrario, amenazando a la criminalidad con males futuros, busca el consenso de las víctimas potenciales de los delitos y, en esta medida, está en tensión permanente e inmediata con las necesidades irracionales de la "democracia penal".

\footnotetext{
${ }^{4}$ De diversa opinión, v. Liszt (vid. su obra citada en la nota 6). También según el modelo de la Escuela de Francfort, que es uno de los más avanzados en el sentido de la integración y de la tematización del papel de las ciencias empírico-criminológicas en el ámbito de la propia teoría del delito (recuerdo, de nuevo, especialmente, HASSEMER, Nomos Kommentar zum StGB, cit., Vor $\$ 1 / 1-242$; y también, entre otros, LÜDERSSEN/SACK (Hrgs.), Seminar: Abweichendes Verbalten, Suhrkamp, Frankfurt a.M., 1975 y ss.; HASSEMER/LÜDERSSEN/NAUCKE, Fortschritte im Strafrecht durch die Sozialwissenschaften?, Müller Verlag, Heidelberg, 1983; LÜDERSSEN (Hrsg.), Aufgeklärte Kriminalpolitike oder Kamp gegen das Böse?, 5 Bände, Nomos Verlag, Baden-Baden, 1998. Vid. también el resto de obras citadas infra, nota 20), el saber criminológico presenta, de hecho, una función sobre todo crítica, de cara a una futura reforma. Su valor en relación con la actividad interpretativo-judicial es necesariamente mucho más modesto.

${ }^{5}$ Sobre el origen del derecho penal como "negación de la venganza", y, por tanto, sobre la función actual del derecho penal de reducir al mínimo el sufrimiento de las víctimas y de los autores de los delitos, previniendo también las respuestas irracionales de las víctimas, FERRAJOLI, Diritto e ragione. Teoria del garantismo penale, Laterza, Bari, 1989, 326 s. Para una reflexión más reciente sobre las relaciones entre derecho penal e irracionalidad, LÜDERSSEN, Über das irrationale im Strafrecht, en Fest. Wolff, Springer, Berlín-Heidelberg, 1998, 325 ss.
} 
Donini - La relación entre Derecho Penal y Política: método democrático y método científico

El máximo (relativo) de la racionalidad legislativa se encuentra normalmente en los códigos (en su construcción originaria). En las leyes especiales y en las reformas de los códigos, se altera siempre o se desfigura la armonía de su estructura.

Hay otras razones históricas que han dificultado una relación equilibrada entre ciencia penal (o ciencia jurídica) y política del derecho. Veámoslas.

\subsection{Las razones históricas y filosóficas de la autonomía científica del derecho (penal) del siglo XIX con respecto a la política. La 'crisis' de las principales razones apuntadas.}

En la atormentada relación: ciencia versus política, ha dominado durante mucho tiempo un modelo de ciencia aristocrática, un modelo de saber autónomo que ha tenido siempre una base normativa y, sólo en ocasiones, también una base empírica. Recordemos algunas razones recurrentes que subyacen al imperativo: Ne Caesar supra gramaticos!

Entre las 'razones' y los postulados de la aristocracia penal podemos enunciar:

a) La exigencia científica de una distinción entre dogmática y política criminal, que reenvía al postulado de la separación de poderes (ejemplar: v. Liszt, y para una lectura actualizada y rica de cultura hermenéutica, Hassemer) ${ }^{6}$.

b) El convencimiento de que exista o prevalezca una descriptividad/neutralidad valorativa del saber científico (Weber, Kelsen)7, de ahí que algunos se hayan lanzado a la búsqueda de una solución con base en la perfectibilidad del drafting legislativo, en la forma en que se escriben las leyes; es una corriente que insiste mucho en el derecho como norma abstracta (taxatividad, reserva de ley, prohibición de la analogía, etc.) y que infravalora al intérprete, además de subrayar las típicas y, ciertamente evidentes, razones de garantía.

c) La versión más extendida, al menos en Italia, ha impuesto la necesidad de la "autonomía del método jurídico" lo que ha conferido durante mucho tiempo al penalista el orgullo de poseer un 'método' autónomo, un know how cualificante e irrenunciable (Arturo Rocco y el tecnicismo jurídico) ${ }^{8}$.

d) La idea de que sobre la verdad y sobre los principios no se decide por mayoría (Dworkin, Ferrajoli)"9; o que las normas-"principio" son objeto de

\footnotetext{
${ }^{6}$ V. LISZT, Über den Einfluss der soziologischen und der anthropologischen Forschungen auf die Grundbegriffe des Strafrechts, en ID., Vorträge und Aufsätze, Bd. II, Walter de Gruyter, Berlín, 1905, 75 ss.; HASSEMER, Strafrechtsdogmatike und Kriminalpolitik, Rowohlt, Reinbek bei Hamburg, 1974, 168 ss.

7 WEBER Max (1904), L'oggetività conoscitiva della scienza sociale e della politica sociale, tr. it. en ID., Il metodo delle scienze storico-sociali, Einaudi, Turín, 1974, 53 ss.; ID (1917), Il significato della "avalutativitâ" delle scienze sociologiche e economiche, tr. it. en Il metodo delle scienze storico-sociali, cit., 309 ss.; ID., Wissenschaft als Beruf (1918), trad. it. Il lavoro intellettuale come professione, Einaudi, Turín, 1971, 5-43 y 28 ss.; KELSEN, Hautprobleme der Staatsrechtslebre entwickelt aus der Lebre vom Rechtssatze, 2. Aufl., Tübingen, 1923, Neudruck Scientia Verlag, Aalen, 1984, 84--94; ID., Reine Rechtslehre, 2. Aufl., Wien, 1960, trad. it., La dottrina pura del diritto, 3 ed., Einaudi, Turín, 1975, 123129.

${ }^{8}$ ROCCO ART., Il problema e il metodo della scienza del diritto penale, en Riv.dir.proc.pen, 1910, 497 ss., también en ID., Opere giuridiche, vol. III, Ed. Del Foro Italiano, Roma, 1933, 263 ss. Para una introducción muy útil al problema del método en el tecnicismo jurídico, MALINVERNI, La Scuola dogmatica del diritto penale, Premiata Tipografia Gallardi, Vercelli, 1939, especialmente, 25 ss., 35 ss., 53 ss.

9 DWORKIN, Taking Rights Seriously (1977), tr.it. I diritti presi sul serio, Il Mulino, Bolonia, 1982, 252 ss., según el cual "no se puede dejar, en justicia, que la mayoría decida sobre derechos por mayoría... permitir que la
} 
REJ - Revista de Estudios de la Justicia - No 4 - Año 2004

una ciencia superior, de un "super derecho penal" antepuesto al legislador histórico que tiene que "deducir" las leyes de esta fuente de razón (neoiusnaturalismo constitucional, constitucionalismo penal extremo).

e) La conciencia de que el derecho penal tiene un carácter no democrático, autoritario e "intolerante" por definición: esto es lo que lo convierte en un instrumento temible, que debe ser continuamente objeto de la legitimación que impone la autonomía de la ciencia respecto de la política.

f) Como consecuencia de todo lo que se ha dicho (en el punto e) surge una corriente que defiende al derecho penal de la instrumentalización de una política irracional o de parte, basada en el consenso o en el poder del consenso, en necesidades emocionales de la colectividad, pero que no se basa en la razón, ya sea ésta una racionalidad de fines o de valores, Zweckrationalität o Wertrationalität (entre tantos, sin mencionar a los más jóvenes, por ejemplo: Noll, Naucke, Bricola, Arzt, Marinucci) ${ }^{10}$.

Los tres primeros postulados hace tiempo que están en crisis, son postulados de carácter cada vez más "relativo".

El postulado de la división de poderes tiene un fundamento constitucional, aunque es evidente que se trata de un principio que conoce articulaciones dialécticas muy fuertes, sobre todo en lo que se refiere a las relaciones entre poder legislativo y judicatura ${ }^{11}$.

mayoría sea juez y parte parece contradictorio e injusto" (ibidem, 253 s.); FERRAJOLI, Democrazia e costituzione (1994), en ZAGREBELSKY/PORTINARO/LUTHER, Il futuro della Costituzione, Einaudi, Turín, 1996,315 ss., 332, en el sentido de que la Constitución no se podría cambiar a golpes de mayoría; ID., Per una storia delle idee di Magistratura Democratica, en N. ROSSI, a cargo de, Giudici e democrazia, Franco Angeli, Milán, 1994,72 s., sobre el garantismo como límite a las decisiones por mayoría en cuestiones relativas a derechos fundamentales. Todas estas tesis no son criticables debido a la idea de que los derechos se sustraigan a las decisiones por mayoría, sino por su 'núcleo'. Pero entre el núcleo genérico y la actuación concreta de cada derecho, incluso fundamental, hay distancias que sólo pueden colmarse con decisiones mayoritarias.

10 A título de ejemplo, se recuardan algunas posiciones "emblemáticas" que son escépticas en relación a la forma (incluso aunque sea "democrática") en que los partidos políticos utilizan el derecho penal. Aunque sea desde posiciones muy diversas: NOLL, Die Berücksichtigung der Effektivität der Gesetze bei ibrer Schaffung, en Methodik der Gesetzgebung, Springer Verlag, Wien-New York, 1982, 131 ss. (todo el desarrollo de la Gesetzgebungslehre en el ámbito penal tiene su origen, entre otras cosas, en los casos de irracionalidad en la producción de las leyes; todo el debate más reciente sobre el derecho penal simbólico y el más relevante sobre el derecho penal de la emergencia, podrían ser considerados aquî); BRICOLA, Rapporti tra dommatica e politica criminale, en Riv.it.dir.proc.pen., 1988, 12 ss.; ID., Legalità e crisi: l'art 25, commi $2^{\circ}$ e $3^{a}$, della Costituzione, rivisitato alla fine degli anni '70, en La Quest. Crim., 1980, 179 ss., 269 s.; ID., Politica criminale e politica penale dell'ordine pubblico (a proposito della legge 22 maggio 1975, n.152), en La Quest. Crim., 1975, 284 ss. (son sólo ejemplos: hay que resaltar, más en general, que el escepticismo hacia la política criminal real de los partidos ha dominado el desarrollo de la perspectiva constitucionalista italiana a partir de los años setenta); NAUCKE, Die Aushöhlung der strafrechtlichen Gesetalichkeit durch den relativistischen, politisch aufgeladenen strafrechtlichen Positivismus, en Institut für Kriminalwissenschaften Frankfurt a.M. (Hrsg.), Vom unmöglichen Zustand des Strafrechts, Peter Lang, Frankfurt a. M., 1995, 483 ss.; ID., Entwicklugen der allgemeinen Politik und der Zusammenhang dieser Politik mit der Reform des Strafrechts in der Bundesrepublik. Deutschland, en ID., Über die Zerbrechlichkeit des rechtsstaatlichen Strafrechts, Nomos Verlag, Baden-Baden, 2000, 393 ss.; ARZT, Wissenschaftsbedarf nach dem 6. StrRG, en ZStW, 111, 1999,757 ss., 763 ss.; ID., Der Ruf nach Recht und Ordnung. Ursachen und Folgen der Kriminalitätsdurcht in den USA und in Deutschland, Mohr, Tübingen, 1976, 163 ss. y passim; MARINUCCI, L'abbandono del codice Rocco: tra rassegnazione e utopia (también en La Quest. Crim., 1981, 297 ss.) en MARINUCCI/DOLCINI, a cargo de, Diritto penale in trasformazione, Giuffrè, Milán, 1984, 327 ss., especialmente, 343 ss.

11 Sobre la dimensión internacional del incremento progresivo del poder judicial, cfr. GARAPON, Le gardien des promesses. Justice et démocratie (1996), tr. it. I custodi dei diritti. Giustizia e democrazia, Feltrinelli, Milán, 1996 ; PIZZORNO, Il potere dei giudici. Stato democratico e controllo della virtù, Laterza, Bari, 1998; TATE VALLINDER (ed.), The Global Expansion of Judicial Power, New York University Press, New York, 1995; 
Donini - La relación entre Derecho Penal y Política: método democrático y método científico

En cuanto a la tesis sobre la neutralidad valorativa de la ciencia jurídica, originariamente rebatida sobre todo por corrientes de inspiración marxista, ya prácticamente nadie la sostiene, aunque es evidente que hay grandes diferencias en la forma de entender el método y los límites del ámbito de valoración del intérprete.

Continúa siendo válida la tesis de la (relativa) autonomía de la ciencia con respecto a la política, que no representa, por otro lado, un motivo suficiente para considerar que aún hoy en día, sea actual el tecnicismo jurídico, salvo que se entienda de forma completamente renovada ${ }^{12}$.

El cuarto postulado de la aristocracia penal (letra d) merecería un amplio examen que no puedo afrontar en este momento ${ }^{13}$, baste resaltar por ahora, que el vicio más destacado de la tesis según la cual sobre los principios no decide la mayoría, consiste en consentir, por el contrario, que se decida sobre ellos por sentencia. Se ha delegado completamente en el poder judicial la "gestión democrática" de los principios ${ }^{14}$; ésta es, en el fondo, la indicación política que proviene también de las posiciones de Dworkin y Ferrajoli. El problema, como veremos (infra $\int 3.0$ ), no es que en el diálogo entre ciencia, política, y judicatura se continúe con la misma política de vetos mutuos, sino que consiste en hacer fiable el papel de concreción de principios en vía hermenéutica que, necesariamente, hay que confiar también a la judicatura.

En realidad, sobre los principios se decide continuamente por mayoría porque sólo su 'núcleo', a veces muy genérico, es indisponible (por ejemplo: "la libertad personal es inviolable", art. 13.1, Cost. Italiana) y todos sabemos que un principio puede ser compatible con al menos cien códigos penales y procesales penales diversos (que constituyen distintos modos de disponer de la libertad). Si estos principios no se concretan de forma democrática y plural, inevitablemente se decidirá sobre ellos de forma autoritaria. El constitucionalismo extremo (neoiusnaturalista) es sólo una forma aún más aristocrática, y si se quiere, también más controlada racionalmente, de tomar esta decisión.

La quinta razón (el carácter autoritario, de defensa extrema, del derecho penal "como tal") sólo es válida respecto a ciertos delitos "naturales" del universo mínimo del derecho penal, el mítico Kernstrafrecht. Incluso aquí se podría discutir mucho respecto a los límites del principio de extrema ratio tal y como se ha aplicado hasta ahora por los legisladores, y también aquí la decisión sancionatoria (más allá de los tipos penales

GUARNIERI/PEDERZOLI, La democrazia giudiriaria, Il Mulino, Bolonia, 1997. Para una relectura de la relación entre democracia, derecho y poder judicial en el marco de su "Diskurstheorie", HABERMAS, Faktivität und Geltung, Suhrkamp, Frankfurt a. M., 1992. Representa emblemáticamente una posición extrema de democracia judiciaria, SCODITTI, Il contropotere giudiæiario, ESI, Nápoles, 1999.

Para reflexiones ya clásicas sobre la relación entre dogmática y política criminal con relación (también) a la distinción de poderes, ROXIN, Kriminalpolitik und Strafrechtssystem, 2. Aufl., Walter de Gruyter, Berlín-New York, 1973, HASSEMER, Strafrechtsdogmatik und Kriminalpolitik, Rowohlt, Reinbek bei Hamburg, 1974, 168 ss.; BRICOLA, Rapporti tra dommatica e politica criminale, en Riv.it.dir.proc.pen., 1988, 3 ss.; PULITANO, voz Politica criminale, en Enc.dir., XXXIV, Giuffrè, Milán, 1985, 91 ss.

12 Una reafirmación puntual de esta exigencia que está, por otro lado, en conexión con la validez permanente del método técnico-jurídico, en PAGLIARO, Principi di diritto penale, parte gen.7, Giuffrè, Milán, 2000, 98.

${ }^{13}$ A este aspecto se dedicará una parte amplia del estudio sobre Democrazia penale, cit.

${ }^{14}$ Ejemplar la posición de SCODITTI, Il contropotere giudizario, cit.; también, por ejemplo, cfr. N. ROSSI, Verso una democrazia maggioritaria. Magistratura e mutamento istituzionale, en ID., a cargo de, Giudici e democrazia, cit., 9 ss., 18 ss. De gran interés sociológico e histórico por su llamamiento directo a la representación del pueblo soberano es la reconstrucción del nuevo poder judicial en GAUCHET, Le révolution des pouvoirs, Gallimard, París, 1995, 35 ss. 
REJ - Revista de Estudios de la Justicia - No 4 - Año 2004

concretos) es claramente susceptible de una respuesta plural. En cuanto nos alejamos de este núcleo irrenunciable de tutela, cuanto más se "extiende" el derecho penal, más se vuelve controvertible, susceptible de ser administrado de forma plural y democrática, más abierto a establecer alternativas a las sanciones más graves, más capaz de "renunciar" a la pena, etc. y, por tanto, y en esta medida, menos se concilia con su imagen clásica, autoritaria e intolerante ${ }^{15}$.

Sólo el sexto postulado continúa siendo integramente válido. Si en el método del penalista hay márgenes legítimos de aristocraticidad que pueden ser considerados, incluso en democracia, legítimos, es porque es preciso controlar la racionalidad del sistema y de la política criminal. Un control puramente mayoritario es, de hecho, una locura. Es intolerable. Llegados a este punto es evidente que una reflexión sobre el 'método de la ciencia' es de una relevancia crucial.

\subsection{E1 "método de la ciencia" y el "método de la democracia" frente a la política judicial en materia penal en conexión con la (más tradicional) concepción del derecho como ciencia hermenéutica e "individualizadora". La imposible supresión de la convivencia entre los modelos neopositivistas y hermenéuticos de ciencia.}

La excesiva valorización del derecho penal como "norma" y del principio de división de poderes ha conducido a la infravaloración del significado del papel institucional de la judicatura como fuente de derecho (diritto/Recht), que no de ley, evidentemente, (legge/Gesezt), y como portadora legítima de corrientes de política interpretativa subordinada a la ley y a la Constitución, pero dotada de márgenes para tomar decisiones autónomas (cfr. supra \0.0. sobre el derecho como "decisión" e "institución"). Hoy en día no hay operador práctico (y tampoco teórico serio) que crea "conocer el derecho" sin "conocer la jurisprudencia".

La distinción misma entre disposición (abstracta) y norma (que deriva de la primera y que puede tener un contenido diverso, según sea interpretada) constituye en la actualidad una de las bases del saber hermenéutico del jurista ${ }^{16}$.

Es un descubrimiento que tiene dos fundamentos, uno relativo al método de la ciencia y otro relativo al método de la democracia:

a) En cuanto al método de la ciencia, se trata de la necesidad de tomar conciencia en el ámbito institucional (y no sólo normativo), de que la aplicación de la ley al caso

\footnotetext{
${ }^{15}$ Este dato se hace especialmente evidente en países como España que han reducido al mínimo la legislación penal complementaria, aunque sólo formalmente en cuanto al número de preceptos, ya que en el código siguen existiendo normas en blanco que remiten a miles de preceptos que están fuera de él: sobre este punto cfr. DONINI, La riforma della legislazione penale complementare: il suo valore "costituente" per la riforma del codice, en ID., a cargo de, La riforma della legislazione penale complementare. Studi di diritto comparato, Cedam, Padua, 2000, 36 s., y sobre la legislación penal especial española: FOFFANI/PIFARRÉ DE MONER, La legislazione penale speciale in Spagna (Codice penale e principio di "universalitä"), ivi, 189 ss.

16 Sobre distinciones similares (aunque las acepciones no sean siempre coincidentes) realizadas en la doctrina italiana por Crisafulli e Tarello, cfr. GUASTINI, Dalle fonti alle norme, Giappichelli, Turín, 1990,15 ss.; ID., Teoria e dogmatica delle fonti, Giuffrè, Milán, 1998, 15 ss., 136 ss., 497 ss.; VIOLA/ZACCARIA, Diritto e interpretazione, Laterza, Bari, 1999, 117 s., 320 ss.; EZQUIAGA GANUZAS, La producción jurídica y su control por el Tribunal Constitucional, Tirant lo Blanch, Valencia, 1999, 41 ss.
} 
Donini - La relación entre Derecho Penal y Política: método democrático y método científico

supone un momento de individualización, y también, al mismo tiempo, que, al aplicar el derecho al caso, se está en condiciones de alcanzar 'nuevos' puntos de vista que son susceptibles de generalización. Es preciso efectuar una nueva reflexión sobre el significado del precedente ${ }^{17}$ que sea coherente con la dimensión del derecho como ciencia hermenéutica (e "individualizadora"18) y no sólo como ciencia "generalizadora" ("ley general y abstracta", "ciencias empíricas", "criminología", "previsibilidad de las decisiones", "previsibilidad del riesgo penal", "causalidad nomológica", "peligrosidad social", "verificabilidad del daño social", "efectividad", etc.). No parece que se haya superado en absoluto la necesidad de una definición contextual del saber jurídico penal que participe tanto de la Geisteswissenschaften, como de la Naturwissenschaften. Al mismo tiempo, el método experimental de las ciencias así llamadas, naturalísticas, aporta al saber penal el control empírico y la prueba de efectividad (infra, $\iiint_{4.0-8.0}$ ), sin el cual el hortus conclusus de nuestra ciencia se parece al de una teología civil.

b) En cuanto al método de la democracia, es preciso responder a la siguiente pregunta: ¿puede pensarse que el pluralismo ideológico opere sólo en el Parlamento y no en la judicatura? ¿puede pensarse que los conflictos que preceden a la formación de la ley puedan milagrosamente desaparecer una vez que ésta ha encontrado una composición dialéctica, una fórmula de compromiso en las pocas palabras de un artículo (10-20 palabras)? ¿Una vez que se promulga la ley debe cesar la "democracia penal", o bien, ser 'administrada' sólo por el pensamiento aristocrático de los académicos o de la Corte Constitucional?

La judicatura realiza, de hecho, una necesaria composición judicial del pluralismo social y de las posturas contrapuestas de las "partes" en el proceso penal ${ }^{19}$. De esta constatación

\footnotetext{
${ }^{17}$ Que en Italia (y en otros países) ha sido estudiado sobre todo por los civilistas. Una antología muy útil de un debate muy amplio ya en los años ochenta, en M. BIN, Il precedente giudiriario, Cedam, Padua, 1995. En la literatura civilista alemana cfr. LANGENBUCHER, Die Entwicklung und Auslegung von Richterrecht, Beck'sche Verlagsbuchhandlung, Munich, 1996. Desde una perspectiva teórica comparada, vid. también la monografía de MARINELLI, Ermeneutica giudiriaria, Giuffrè, Milán, 1996, 29 ss. y passim. Entre los penalistas, cfr. la importante monografía de CADOPPI, Il valore del precedente nel diritto penale, Giappichelli, Turín, 1999. Me gustaría únicamente precisar que la necesidad de estudiar el precedente "vinculante" se puede reconducir a una reducción del caos interpretativo y, por tanto, se coloca en una perspectiva de recuperación de la legalidad efectiva (in action)- éste es, por ejemplo, el punto de vista de Cadoppi - que al mismo tiempo constituye un reconocimiento evidente del papel de la jurisprudencia como fuente de derecho (una vez superadas, incluso en los países anglosajones, las concepciones "declarativas" del precedente). Desde este punto de vista es importante recordar que en el contexto social no existe únicamente la interpretación autoritaria del juez, sino que respecto a un número enorme de cuestiones que no llegan a los tribunales, desempeñan un papel hermenéutico y de consulta tanto la abogacía como los aparatos administrativos de la Administración Pública, diversos operadores jurídicos privados, etc.; no existe, por tanto, únicamente el punto de vista del juez que, a menudo, y frente a la controversia, tiene en cuenta una hermenéutica consolidada que opera "en el ámbito social" mucho antes que "en los tribunales": cfr. a propósito las observaciones de TWINING/MIERS, How to Do Things with Rules (1982), trad. it., Come far cose con regole, Giuffrè, Milán, 1990, 238 ss., 272 ss. Se trata de un aspecto relevante para la comprensión de la relación entre pluralismo y papel del juez (vid. más ampliamente infra, en el texto).

${ }^{18}$ Ya RADBRUCH, Rechtsphilosophie ${ }^{8}$, a cargo de E: Wolf y H.P. Schneider Verlag, Stuttgart, 1973, 216 s.

${ }^{19} \mathrm{Sin}$ necesidad de citar aquí de nuevo (ya que las citas serían tan evidentes como exactas) la Diskurstheorie de Habermas, para un 'radiografía' de notable eficacia representativa de la crisis de la cultura estatalista de la "izquierda" italiana y de los efectos que tiene hoy respecto a las funciones de quien juzga, cfr. ALBANO, Crisi dello stato sociale, limiti della cultura statualistica e ruolo del giudice, en ROSSI, Giudici e democrazia, cit., $144 \mathrm{ss}$. El papel mediador del juez en una sociedad pluralista ha sido también objeto de interpretaciones más allá de la correcta ubicación constitucional de los poderes, interpretaciones cercanas al así llamado uso alternativo del derecho conforme al estilo de los años setenta, del que claramente pretendo distanciarme: cfr. por ejemplo, SCODITTI, Riforma costituzionale e giurisdizione, en Democrazia e diritto, 1997, 1 ss., y especialmente, 48 ss.
} 
REJ - Revista de Estudios de la Justicia - No 4 - Año 2004

surge la necesidad de que la ciencia penal elabore instrumentos conceptuales que integren ordenadamente ese componente del derecho como hermenéutica y ciencia del espíritu, que en la aplicación judicial al caso valoriza el derecho como decisión. No es casual que el estudioso se dedique sobre todo a los "casos difíciles" (hard cases), puesto que en los casos fáciles 'funciona' todavía muy bien, revisado y corregido (con componentes valorativos), el paradigma de la interpretación como actividad "declarativa" o como silogismo judicial (después de la interpretación). Y esto es así porque en los casos fáciles, aunque el intérprete "valore", alcanza soluciones consolidadas por una amplia mayoría. Por este motivo los casos son "fáciles" y se puede realizar un silogismo. Es en los casos difíciles en los que el modelo no funciona en absoluto ${ }^{20}$.

La integración del método científico (ya) neopositivista, que es todavía tan "atrayente" por su seductora exactitud y precisión y el método hermenéutico y de las ciencias de la cultura, sólo puede realizarse bajo el signo del método democrático y del reconocimiento del papel institucional de la judicatura, también penal, en la gestión de los conflictos y del pluralismo ${ }^{21}$.

A medida que se han ido extendiendo las formas de privatización del proceso (mecanismos de negociación sobre el rito, la condena y la prueba, relevancia, incluso probatoria, de las pruebas realizadas por el abogado defensor - en virtud de la ley de 7 de diciembre de 2000, n. 397 que prevé precisamente una serie de disposiciones sobre las pruebas realizadas por la defensa -) se ha ido acentuando la función del proceso como composición del conflicto entre las partes, más que como procedimiento de verificación autoritaria de la verdad (esta segunda función se mantiene, evidentemente, aunque conviva con las demás), lo que se concilia con el papel del juez como mediador del pluralismo dentro del Estado y de la sociedad, más que como portador de una única y constante verdad autoritaria, pronunciada "desde fuera", sobre los valores y las razones de los contendientes. Para una representación muy eficaz de las diversas funciones del proceso en los sistemas adversarial respecto a los inquisitorios, DAMAŠKKA, I volti della giustizia e del potere. Analisi comparatistica del proceso, Il Mulino, Bolonia, 1991, passim. Sobre la entrada de las formas de negociación en el proceso penal, vid. la monografía de SINNER, Der Vertragsgedanke im Strafprozeßrecht, Peter Lang, Frankfurt, a.M., 1999 con una visión muy amplia de la situación italiana, vista desde una posición muy hostil a la negociación.

${ }^{20}$ Cfr. también DONINI, Dogmatica penale e politica criminale a orientamento costiturionalistico, cit., 53 ss. Sobre este tema existe una literatura inabarcable, sobre todo de common law. Me remito únicamente a DWORKIN, Taking Rights Seriosuly, trad. it. cit., 171 ss.; ID., No Right Answer? (1978), trad. it., Non c'è soluzione corretta?, en Materiali per la storia della cultura giuridica, 1983, 469 ss. (con una fe excesiva en la "corrección" y univocidad de las decisiones judiciales sobre tales casos); y todavía mejor a MacCORMICK, Legal Reasoning and Legal Theory, Clarendon Press, Oxford, 1978, 175 ss.; y a BARAK, Judicial Discretion (1987), trad. it., La discrezionalitâ del giudice, Giuffré, Milán, 1995, 45 ss., 115 ss.

21 Un ejemplo paradigmático de la integración entre saber hermenéutico, saber nomológico y exigencias de la praxis en el método del penalista se encuentra continuamente en numerosas, aunque muy diversas entre ellas, obras de la Escuela de Francfort: cfr. por ejemplo ( $\sin$ referencias específicas a los trabajos de los estudiosos de las últimas generaciones de la Escuela) HASSEMER, Tatbestand und Typus. Untersuchungen zur strafrechtlichen Hermeneutik, Carl Heymann’s Verlag, Köln-Berlín-Bonn-Munich, 1968; ID., Strafrechtsdogmatik und Kriminalpolitik; cit., Theorie und Soziologie des Verbrechens, Europäische Verlagsanstalt, Athäneum Verlag, Frankfurt a.M., 1973; ID., Über die Berücksichtigung von Folgen bei der Auslegung der Strafgesetze, en Fest. Coing, Bd. I, Beck, Munich, 1982, 493 ss.; ID., Prävention im Strafrecht, en Juristische Schulung, 1987, 257 ss.; ID., Einführung in die Grundlagen des Strafrechts ${ }^{2}$, Beck, Munich, 1990; ID., Nomos Kommentar, cit., Vor $\int 1 ;$ ARTH. KAUFMANN/HASSEMER, Einführung in die Rechtsphilosophie und die Rechtstheorie der Gegenwart, C.F. Müller, Heidelberg, 1989 (y las ediciones sucesivas); NAUCKE, Über die juristische Relevanz der Sozialwissenschaften, Metzner, Frankfurt a.M., 1972; NAUCKE, Grundlinien einer rechtsstaatlich-praktischen allgemeinen Straftatlebre, Franz Steiner Verlag, Wiesbaden, 1979; también de Naucke cfr. la recopilación de trabajos en ID., Über die Zerbrechlichkeit des rechtsstaatlichen Strafrechts, Nomos, Baden-Baden, 2000; ID., Gesetalichkeit und Kriminalpolitik, Vittorio Klostermann, Frankfurt a.M., 1999; LÜDERSSEN/SACK (Hrsg.), Seminar: Abweichendes Verhalten, cit.; HASSEMER/LÜDERSSEN/NAUCKE, Hauptprobleme der Generalprävention, Metzner, Frankfurt a.M., 1979; HASSEMER/LÜDERSSEN/NAUCKE, Fortschritte im Strafrecht durch die Sozialwissenschaften?, cit.; LÜDERSSEN (Hrsg.), Aufgeklärte Kriminalpolitik oder Kamp gegen das Böse?, cit.; ID., Abschaffen des Strafens?, Suhrkamp, Frankfurt a.M., 1995. 


\subsection{La extensión del "paradigma aristocrático" también al ámbito judicial. Empirismo y valores en el método dl Tribunal Constitucional. El derecho penal como teología civil o como ciencia social.}

Aún hoy en día en Italia el mito "garantista" del juez neutral y bouche de la loi se refleja a menudo en las obras de los penalistas nostálgicos del Iluminismo del siglo XVIII (el retraso del penalista medio italiano en materia hermenéutica es sorprendente ${ }^{22}$ ) y también en políticos nostálgicos de una judicatura poco intervencionista respecto a los "poderes fuertes" (fuerte con los débiles y débil con los fuertes) ${ }^{23}$.

Además, la tradicional cultura separada, aristocrática y autoritaria del penalista ha comprometido y cooperado necesariamente también al estilo de los jueces que, a menudo, cuando reflejan corrientes más 'intervencionistas', se sienten portadores de orientaciones autónomas, e incluso separadas, respecto a las de la sociedad civil. Pero incluso cuando el estilo de la jurisprudencia penal, al intervenir en la realidad, no es simplemente antagonista o superior, sino dialogístico respecto a los debates, interpretaciones jurídicas y tensiones del contexto social, sigue estando mediatizado de forma rigurosa por las normas. Es aquí donde se encuentran límites objetivos impuestos por la división de poderes que hace que sea modesta, aunque no irrelevante o indiferenciada, la medida del saber empírico utilizable por el juez, y, especialmente: 1) por el juez ordinario; 2) por el juez constitucional.

El juez ordinario tiene muchos programas condicionales (reglas construidas sobre un paradigma operativo: si... entonces...), que circunscriben fuertemente, si no su conocimiento de la realidad, sí las decisiones que se pueden tomar: la quaestio facti está nítidamente delimitada por las quaestiones iuris abstractamente admisibles, y entre las reglas abstractas que le vinculan, está también la prohibición de la analogía in malam partem, que sirve también, evidentemente, para excluir cualquier clase de valoración orientada a las consecuencias que tenga como resultado la violación de esta regla. Por todo ello, el problema depende siempre del tipo de regla (de los "programas condicionales") que el legislador le haya confiado.

El juez constitucional, por el contrario, tiene más programas de fines (normasprincipio, valores, etc.) a pesar de que también gestione muchas normas-reglas ${ }^{24}$. Evidentemente, también está vinculado por el principio de división de poderes, que no supone que no pueda disponer de saber empírico, o bien adquirirlo mediante

22 Para una orientación finalmente abierta a la perspectiva de la hermenéutica contemporánea, vid. FIANDACA, Ermeneutica e applicarione giudiriale del diritto penale, conferencia impartida en Perugia en el Congreso sobre "L'interpretazione della legge alle soglie del XXI secolo" en los días 16-18 de diciembre de 1999.

${ }^{23}$ Y ello a pesar del hecho de que en Italia la judicatura tiene un papel mucho más fuerte que el de la ciencia académica: el Parlamento puede normalmente "permitirse" aprobar una ley contra la opinión de la academia, pero es mucho más cauteloso cuando se trata de hacerlo contra la opinión de la judicatura. No me refiero aquí a la judicatura "de izquierdas", sino a la judicatura en general. Sin embargo, ha sido la corriente de izquierda de la judicatura italiana la que ha contribuido, de forma determinante, a promover una dimensión política fuerte en el tercer poder. Me remito a PALOMBARINI, Giudici a sinistra. I 36 anni della storia di Magistratura democratica: una proposta per una nuova politica per la giustizia, ESI, Nápoles, 2000, y al citado volumen Giudici e democrazia, a cargo de N. Rossi, cit.

${ }^{24}$ Sobre esta característica de la hermenéutica constitucional, me remito únicamente (aunque también aquí las referencias podrían ser muy numerosas) a MENGONI, L'argomentazione nel diritto costiturionale, en ID., Ermeneutica e dogmatica giuridica. Saggi, Giuffrè, Milán, 1996, 115 ss. 
REJ - Revista de Estudios de la Justicia - No 4 - Año 2004

investigaciones técnicas. Sin embargo, el juez constitucional no dispone en Italia de la facultad de ordenar pericias, -contrariamente, por ejemplo, a la situación del juez constitucional alemán del Bundesverfassungsgericht ${ }^{25}$, que en teoría podría utilizarse también de forma amplia para examinar (si es posible) la efectividad de las leyes y el respeto al principio de subsidiariedad o la taxatividad de la ley en relación con su aplicabilidad práctica, con su verficabilidad procesal ${ }^{26}$.

Otro déficit de democraticidad de la cultura judicial italiana está constituido por el hecho de que no se prevea, ni siquiera en la Corte Constitucional, el derecho de manifestar y motivar la dissenting opinion - contrariamente al voto particular en España y al Sondervotum en Alemania ${ }^{27}$.

Si la perspectiva constitucionalista en derecho penal supone un juez, muy valorativo, que valora muchísimo, ya que debe controlar cada ley e interpretarla a la luz de principios superiores de rango constitucional ${ }^{28}$, no es menos cierto que la ya indicada división de poderes marca algunas fronteras estrictas a esta capacidad que es potencialmente abstracta; de hecho, a la hora de verificar los principios de extrema ratio/subsidiariedad y racionalidad, el control desarrollado por la Corte Constitucional italiana sobre la política criminal del legislador, ha admitido límites a estos poderes. En la alternativa entre punición administrativa o penal, peligro concreto o abstracto-concreto (no presunto) el control que puede realizarse tiene un margen de intervención muy estrecho, ya que la Corte se reserva la posibilidad de superar la prohibición de revisión política sobre la actividad del Parlamento (art. 28.111 de marzo de 1953, n.87) sólo frente a la (evidente) irracionalidad de la decisión tomada por el legislador ${ }^{29}$. No obstante y desde hace tiempo, la Corte ha puesto en marcha, en el marco de estas barreras normativas, formas de control de racionalidad respecto a valores (Wertrationalität) y de racionalidad respecto a fines (Zweckerationalität) ${ }^{30}$ también en el ámbito penal.

25 HASSEMER, en Nomos Kommentar, cit., Vor $\$ 1 / 35,140$. El Tribunal Constitucional alemán, por otra parte, parece utilizar el poder de ordenar pruebas de forma muy limitada. Para un ejemplo significativo en materia de aborto, vid. BVerfG 28.5.1993, Bd. 88, 203 ss.

${ }^{26}$ Se identifica con el principio de determinación hoy en día, la necesidad de que las normas penales describan hechos "susceptibles de ser probados en el proceso", MARINUCCI/DOLCINI, Corso di diritto penale ${ }^{2}$, Giuffrè, Milán, 1999, 99 s. (el aspecto de la suficiente determinación en abstacto, o taxatividad, es reconducido por los Autores al "principio de precisión": ivi, 57 ss.). Más allá de la proliferación de categorías doctrinales es muy importante que cuando se le reconoce a un órgano institucional el poder de controlar la practicabilidad de las leyes, se le dote también de los poderes necesarios para llevarlo a cabo: sin pruebas, ¿a qué saberes podrá acudir el Tribunal si no a banales y claras "evidencias"? De esta forma, sólo podrá decidir en casos extremos: y esto es lo que probablemente pretende obtener la limitación del control actual de los presupuestos fácticos (empíricos o científicos) de la legislación vigente.

27 Sobre la historia de la introducción en el ordenamiento del Tribunal Constitucional alemán del voto particular, LAMPRECHT, Richter contra Richter. Abweichende Meinungen und ibre Bedeutung für die Rechtskultur, Nomos Verlag, Baden-Baden, 1992.

28 Sobre las características del tipo de juez que presupone la perspectiva constitucional, cfr. DONINI, L'art. 129 del Progetto di revisione costituzionale approvato il 4 novembre 1997, en Critica del diritto, 1998, 122 s.; ID., Dogmatica penale e politica criminale a orientamento costiturionalistico, cit., 56 ss.

${ }^{29}$ Vid. en concreto, sobre los límites de tal poder, Corte cost., 6 julio-18 julio 1989 n. 409, en Giur.cost., 1989, 1906 ss., especialmente, 1916 s.; Corte cost., 10-11 julio 1991, n. 333, en Giur. Cost., 1991, 2646 ss., especialmente, 2658-2661.

${ }^{30}$ No puedo aquí desarrollar el discurso mediante una remisión a las decisiones sobre esta materia (que radican, como normas "demostrativas" de la Constitución italiana que fundamentan las decisiones de ilegitimidad constitucional, sobre todo en los artículos 3.1: sub specie racionalidad y proporcionalidad; y 25. 2: sub specie taxatividad-determinación): de todas formas, como ejemplo de verificación de racionalidad respecto a fines, recuerdo: Corte cost. , 15-28 diciembre 1995, n. 519, que declaró la ilegitimidad del art. 670.1 del C.P sobre la mendicidad no invasiva ( que no utiliza medios repugnantes, vejatorios, o medios fraudulentos), 
Donini - La relación entre Derecho Penal y Política: método democrático y método científico

El programa de Franco Bricola (y con él el de otros penalistas) que preveía el control por parte de la Corte de todas las normas penales que no tutelasen bienes de relevancia constitucional contra agresiones de peligro concreto ha quedado como un mero programa político $^{31}$. E, incluso, podría decirse que ha sido, precisamente en el plano político, en el que este programa no ha sido aceptado por la doctrina italiana dominante; si hubiese convencido a ese nivel, hubiese sido posible considerarlo 'acogido' en la Constitución vigente $^{32}$. Y así lo ha confirmado la fallida experiencia de la Comisión Bicameral para la revisión de la Constitución (1997/1998) que en el art. 129.1 y 2, intentó traducir en norma constitucional el programa de Bricola: «Las normas penales tutelan bienes de relevancia constitucional/No es punible la comisión de un hecho previsto como delito si no ba comportado una ofensividad concreta» ${ }^{33}$.

Se trató, de hecho, de un intento de ampliar los poderes de control de la Corte sobre la racionalidad de las decisiones político-criminales del Parlamento, a través del examen

como una incriminación inidónea para tutelar los bienes jurídicos (por ejemplo, la tranquilidad pública) para cuya protección había sido construída por el legislador de 1930; igualmente significativa Corte cost. 17 octubre-2 noviembre 1996, n. 370, sobre el delito de sospecha del art. 708 del C.P (posesión injustificada de valores), declarado ilegítimo (entre otras cosas) porque " ya no es adecuado para perseguir el fenómeno del enriquecimiento ilícito tal y como resulta de la observación de la realidad criminal de estos últimos decenios". Como ejemplo, por el contrario, de norma ilegítima por la irracionalidad respecto a valores, cfr. los artículos 1 y 3 1. 24 de junio 1929, n. 1085, considerada tal por la Corte cost. 21-25 de mayo 1987, n. 189, sobre la exposición no autorizada (en el territorio nacional italiano) de una bandera de un Estado Extranjero: superado el clima político de los veinte años de fascismo y de su nacionalismo, el Tribunal ha declarado que la sanción penal resulta "hoy manifiestamente irracional...el hecho mismo carece de cualquier objeto jurídico específico y de la mínima ratio incriminand?'. Para un análisis reciente de la imbricación entre taxatividad, proporcionalidad y racionalidad en las decisiones del Tribunal, cfr. PALAZZO, Offensività e ragionevolezza nel controllo di costituzionalità sul contenuto delle leggi penali, en Riv.it.dir.proc.pen., 1998, 350 ss.; MAUGERI, I reati di sospetto dopo la pronuncia della Corte costituzionale n. 370 del 1996: alcuni spunti di riflessione sul principio di ragionevolezza, di proporzione e di tassatività, parte I, en Riv.it.dir.proc.pen, 1999, 434 ss.

31 Para un balance de las tesis de Bricola en contribuciones recientes, baste aquí recordar, DOLCINI/MARINUCCI, Costituqione e politica dei beni giuridici, en questa Rivista, 1994, 333 ss., 345 ss.; M. ROMANO, Commentario sistematico del codice penale ${ }^{2}$, vol. I, Giuffrè, Milán, 1995, Pre-Art. 39/1-16; FIANDACA/MUSCO, Diritto penale, parte gen. ${ }^{3}$, Zanichelli, Bolonia, 1995, 12-28; DONINI, Teoria del reato. Una introdurione, Cedam, Padua, 1996, 18-47, 130-140; PADOVANI, Diritto penale, parte gen.5. Giuffrè, Milán, 1999, 110 ss.; PALAZZO, Introdurione ai principi del diritto penale, Giappichelli, Turín, 1999, 142 ss.; DONINI, voce Teoria del reato, in Dig.Disc.Pen., vol. XIV, Utet, Turín, 1999, 265-274.

32 He desarrollado este aspecto en una intervención sucesiva al congreso en ocasión del cual se elaboró inicialmente el presente trabajo: cfr. DONINI, Ragioni e limiti della fondazione del diritto penale sulla Carta costituzionale. L'insegnamento dell'esperienza italiana, en Il Foro it., 2001, V, 29 ss., conferencia pronunciada en Salamanca, en los Cursos de Postgrado en Derecho, enero de 2001, también en trad. española, a cargo de Cristina MÉNDEZ RODRÍGUEZ, Un derecho penal fundado en la carta constitucional: razones y limites. La experiencia italiana, en Revista penal, n. 8/2001, 24 ss., y también en Responsa Iurisperitorum Digesta, vol. II, Ediciones de la Universidad de Salamanca, Salamanca, 2001, 223 ss.

${ }^{33}$ Los puntos 3 y 4, a su vez, preveían: "Las normas penales no pueden ser interpretadas de forma analógica o extensiva./Sólo se admitirán nuevas normas penales si modifican el Código penal o bien, si se contienen en leyes que disciplinen orgánicamente la entera materia a la que se refieren". Sobre el art. 129 de la Comisión bicameral en general, cfr. por ejemplo, las críticas de FIANDACA, Intervento al dibattito su "Giustizia penale e riforma costituzionale nel testo approvato dalla Commissione bicamerale”, en Critica del dir., 1998, 143-145; ID., La legalità penale negli equilibri del sistema politico-costituzionale, en Foro it., 2000, V, 137 ss., 141 s., y de PALAZZO, Le riforme costituzionali proposte dalla Commissione bicamerale, B) diritto penale sostanziale, en Diritto penale e processo, 1998, 41; cfr. también DI GIOVINE, L'evoluzione dell'art. 25 Cost. nel pensiero del nuovo costituente, en Cass. Pen., 1998,356 ss. Hay que destacar que muchas críticas estaban bien fundadas o eran comprensibles (especialmente las que se referían a la prohibición de interpretación extensiva o las atinentes a la difícil gestión del principio relativo a la tutela de bienes de rango constitucional, tal y como he tenido ocasión de aclarar ampliamente en L'art. 129 del Progetto, cit.): lo que por el contrario asombra, es la resistencia preconcebida, precisamente en Italia, a una legislación penal constitucional mejor, confiando únicamente en las reformas ordinarias. 
sobre si los bienes jurídicos son o no, de relevancia constitucional. Hoy podemos preguntarnos: ¿era un modelo de aristocracia penal, o de mayor democracia judicial? ¿era un modelo que permitía perfeccionar instrumentos críticos y verificables para controlar la ley, o que suponía una politización "incontrolable" de la Corte Constitucional? Considero, como he escrito en otro lugar, que a pesar de la existencia de varios riesgos superables, se podría haber conseguido imponer, a través de un control mayor de la Corte, una mayor racionalidad y también verificabilidad empírica sobre las decisiones incriminadoras, siempre que los nuevos principios se hubiesen injertado en un tejido normativo de leyes ordinarias que les hubiesen concretado desde el principio de forma más operativa de la que sería posible hoy a la luz de la actual legislación penal. Cierto es que aún tendremos que esperar.

La ciencia penal académica por su parte -y con respecto a ello me remito a lo que he dicho sobre las razones "políticas" de la poca acogida de la tesis de Bricola-, se ha centrado exclusivamente en la reforma ordinaria: frente a la continua irracionalidad de las leyes penales vigentes (no sólo en Italia, ciertamente) cree que únicamente a través de la ley ordinaria se puede conseguir la racionalidad de la legislación. No se quieren incrementar los poderes de control de la Corte, temiendo excesos de democracia judicial, esto es, constituir un "garante de la Constitución" sin controles. Pero no se trata, que quede claro, de una "fe renovada en la política", sino, más bien, de una falta de confianza en un Tribunal demasiado fuerte ${ }^{34}$. Es por tanto, una doble desconfianza la que ha neutralizado propuestas institucionales innovadoras.

Nos arriesgamos así a perpetuar el papel de la Corte como un tribunal de teología civil que argumenta sólo con valores (controlando la Wertrationalität) y que no tiene conocimiento empírico, ya que incluso el control de la Zweckerationalität se atiene a los "fines" y no a las consecuencias, esto es: una idoneidad respecto a los fines que no está sustentada por un saber científico.

El máximo de «saber empírico» que utiliza la Corte en el ejercicio del control sobre la conformidad de las incriminaciones a los valores o a los objetivos del legislador, es un llamamiento genérico a las experiencias legislativas extranjeras, que se tienen en cuenta para afrontar el juicio sobre el retraso, incongruencia o irracionalidad de una regulación nacional ${ }^{35}$.

A pesar de que el control de constitucionalidad en Italia presente estos límites institucionales, es preciso subrayar el gran significado europeo y democrático que tiene la perspectiva constitucionalista fruto de la cultura penal italiana (desde Pietro Nuvolone, Marcello Gallo y Franco Bricola en adelante): no se ha tratado de la contribución de un solo estudioso iluminado, sino más bien, de un movimiento coral de la cultura penalista, un movimiento transversal a todas las escuelas, que ha originado un gran debate también en la judicatura

\footnotetext{
34 Para una valoración sustancialmente positiva de las propuestas del art. 129 de la Comisión Bicameral, por lo menos respecto a los puntos 1 y 2, con puntos de vista diversos, cfr. MAZZACUVA, Intervento al dibattito su "Giustizia penale e riforma costituzionale nel testo approvato dalla Commissione bicamerale", en Critica del dir., 1998,155 ss.; CASTALDO, Welches Strafrecht für das neue Jahrtausend?, de próxima publicación en Fest. Roxin, 11 ss. (del dactilografiado). Vid. también mi trabajo, ya citado, DONINI, L'art. 129 del Progetto, cit., 95 ss.

35 Se repiten las remisiones (aunque a menudo sean fugaces) a ordenamientos extranjeros, normalmente europeos, en las sentencias de la Corte Constitucional italiana n. 96/1981 (sobre el delito de plagio), n. 364/1988 (sobre la ignorancia de la ley penal), n. 1085/1088 (sobre el hurto de uso) n. 391/1994 (sobre el delito de ultraje), n. 519/1995 (sobre mendicidad), n. 370/1996 (sobre delitos de sospecha).
} 
Donini - La relación entre Derecho Penal y Política: método democrático y método científico

ordinaria. Ha sido una ciencia penal crítica, que no se ha centrado en la legitimación de lo que ya existía, una ciencia penal construida sobre "principios" y no sólo sobre "reglas" o "categorías sistemáticas"; ha sido una ciencia penal que ha sabido inspirar y orientar las decisiones del Tribunal Constitucional maduradas sobre todo a partir de finales de los años ochenta.

Cuando hoy en día y desde Alemania se acusa violentamente a la perspectiva constitucionalista del derecho penal (sin referencias, por otra parte, a la experiencia italiana) de representar únicamente una forma de iusnaturalismo ${ }^{36}$, se expresa lo que constituía un motivo comprensible de preocupación (que yo mismo he tenido) frente a concepciones (todavía) rigurosamente individualistas, deductivistas o "filosóficas" de las normas constitucionales propias de los años setenta y ochenta. Sin embargo, el debate plural, que ha tenido por objeto a las normas constitucionales, ha neutralizado, de hecho, el riesgo de una lectura no discursiva, sino aristocrático-iusnaturalista de esas normasprincipio.

\subsection{La "política" que cultivan los científicos: el idealismo de la, así denominada, ciencia "funcionalista", o bien orientada en sentido "político-criminal", u orientada "a las consecuencias", pero no empíricamente.}

El penalista ama una sola clase de política: la que imagina que subyace a sus diseños teóricos, que únicamente aportan al sistema penal una patente de legitimación. Es la política imaginaria de un nuevo sistema, de un nuevo método. No es la política real del sistema, sino su embellecimiento, salvo que el legislador haya acogido efectivamente las indicaciones que provienen de los estudiosos.

Si se prescinde de esa forma de política, de lo más singular, representada justamente por el tradicional método dogmático 37 y por las interpretaciones conformes con la Constitución, es ciertamente dudoso que exista hoy en día en Italia una política criminal real de matriz académica (limito esta observación a mi país, pero sería posible extenderla a otros países). No existe en absoluto una clara política criminal europea, de matriz académica y que sea realmente representativa. La política criminal real no proviene de la "ciencia". O bien proviene de la ciencia "que representa" las decisiones de los gobiernos.

Por otra parte, desde los años setenta en adelante se ha hablado mucho (en Alemania, en Italia, en España, etc.) de política criminal "mezclada" con la dogmática, y gestionada por el intérprete (el programa de Roxin en Alemania; el de Bricola en Italia, y varias corrientes de orientación constitucionalista).

36 NAUCKE, Die Legitimation strafrechtlicher Normen - durch Verfassung oder durch überpositive Quellen? en LÜDERSSEN, Aufgeklärte Kriminalpolitik oder Kampf gegen das Böse? Bd. I, Nomos Verlagsgesellschaft, BadenBaden, 1998, 156 ss.: este trabajo de Naucke representa, en mi opinión, una agresión tan fuerte como injustificada a la perspectiva constitucionalista en general. Los diversos aspectos y la tentación por el neoiusnaturalismo, han sido discutidos frecuentemente en el debate italiano (por ejemplo, por Fiandaca, Ferrajoli y por quien escribe), pero en un contexto argumentativo radicalmente diverso, como ya se ha apuntado en el texto.

37 Sobre el método dogmático tradicional como argumentación "política", de la política de la doctrina, lejana de la praxis, y heredera de un estilo de pensamiento que tiene su origen en el siglo XIX, cfr. NAUCKE, Über das Verbältnis von Strafrechtswissenschaft und Strafrechtspraxis, en ZStW, 85, 1973, $425 \mathrm{~s}$. 
Pero no ha sido a menudo una política basada en datos empíricos o en el conocimiento de la efectividad y de las funciones reales del derecho penal respecto a los sistemas que le son alternativos. Ha sido una política que ha observado en la propia ley algunos "fines" y que ha querido reinterpretar el sistema penal a la luz de esos fines. O ha sido, como en Italia, una política que se ha deducido de principios constitucionales superiores (o bien pensada para prescindir de ellos, pero "reconducida" en vía hermenéuticaargumentativa a normas-principio o normas constitucionales) $)^{38}$.

Desde puntos de vista a menudo muy diversos, algunos han hablado de «unciones» ${ }^{39}$ y otros de «orientación a las consecuencias» ${ }^{40}$.

38 En la doctrina italiana se contiene un auténtico manifiesto sobre el nuevo curso de la dogmática que se orienta a objetivos de política criminal con base constitucional en MOCCIA, Il diritto penale tra essere e valore, ESI, Nápoles, 1992: casi una síntesis ideal de las diversas experiencias metodológicas de Roxin y de Brícola. También de Moccia, vid. igualmente el llamamiento a la necesidad de aunar eficiencia y garantías en ID., La perenne emergenza. Tendenze autoritarie nel sistema penale, ESI, Nápoles, 1995, 153 ss.

39 A pesar de sus "manifiestos" programáticos o de sus reflexiones metodológicas, no están siempre claras, por ejemplo, las diferencias entre el método orientado a los fines de la pena, o bien teleológico-funcional, o funcional tout court, diseñado, por ejemplo, por autores como Roxin (ROXIN, Strafrecht, AT ${ }^{3}$, Bd. I, Beck, Munich, 1997, S 7/24 ss.; ID., Zur kriminalpolitischen Fundierung des Strafrechtssystems in Fest. Kaiser, Bd. I, Duncker \& Humblot, Berlín, 1998, 885 ss.), Wolter (cfr. WOLTER, Objektive und personale Zurechnung von Verhalten, Gefahr und Verletzung in einem funktionalen Straftatsystem, Duncker \& Humblot, Berlín, 1981, 21 ss. y passim, donde „funktional“ y „teleologisch“son, sustancialmente, sinónimos), Frisch (sobre su concepto „funzionale“ de dolo cfr. FRISCH, Vorsatz und Risiko, Carl Heymanns Verlag, Köln-Berlín-Bonn-Munich, 1983, 42 ss., 46 ss.), Schünemann ( para una reflexión clarificadora sobre el método de la ciencia alemana del siglo XX, desde una perspectiva histórica, cfr. SCHÜNEMANN, Einführung in das strafrechtliche Systemdenken, en ID. (Hrsg.), Grundfragen des modernen Strafrechtsystems, Walter de Gruyter, Berlín-New York, 1984,1 ss., especialmente 45 ss., donde "zweckrational" y "funktional"se usan, igualmente, como sinónimos, de la misma forma que lo hace a continuación Roxin; cfr. También de SCHÜNEMANN, Strafrechtssystem und Kriminalpolitik, en Fest. R. Schmitt, Mohr, Tübingen, 1992, 117 ss., especialmente 125 ss.), o Jakobs (cfr. por ejemplo. JAKOBS, Strafrecht, AT ${ }^{2}$, Walter de Gruyter, Berlín-New York, 1991, VII s. (Aus dem Vorwort zur ersten Auflage), \17/18 ss., 22, y nota 46b, p. 484; ID., Das Strafrecht zwischen Funktionalismus und „,alteuropäischem“ Prinzipiendenken, en $Z S t W, 107,1995,843$ ss.): es decir, no es el método el que explica la diversidad de resultados (a menudo se trata de argumentaciones diversas, no de soluciones diversas), sino la diferencia entre los objetivos que los diversos autores consideran que tengan o deban tener la pena o el sistema penal. Las 'funciones' son como los 'objetivos', es decir, sólo sinónimos de un deber ser asignado a las instituciones y a las categorías penales. Incluso quien utiliza el término en un sentido descriptivo, no se sustrae a su utilización también prescriptiva. Es evidente que cambiando los objetivos, en función de los diversos puntos de vista, o de la diversa sensibilidad política de los distintos intérpretes, cambian las argumentaciones del "funktionales Denken", pero no siempre cambian las soluciones efectivas. Cfr. también la óptima introducción a la obra de Jakobs elaborada por PEÑARANDA RAMOS/SUÁREZ GONZÁLEZ/CANCIÓ MELIÁ, Consideraciones sobre la teoría de la imputación de Günther Jakobs en JAKOBS, Estudios de Derecho penal, a cargo de los mismos Autores, ed. Cívitas, Madrid, 1997, 17 ss., donde se relativiza justamente (ibidem, 24 ss., 37) la distancia entre las posiciones del autor y las de la doctrina alemana dominante. Sin embargo, la diferencia existe y es una diferencia de sensibilidad política sobre un uso más crítico, o bien únicamente "comprensivo" del sistema penal. En un caso, la distancia entre ser y deber ser es o (a veces) parece mayor, en el otro caso tiende a desaparecer. De esta forma nos encontramos con perspectivas teleológico-"funcionales" relativas a principios (por ejemplo, Roxin, Schünemann, etc.), y otras que son menos sensibles a estos aspectos (por ejemplo, Jakobs).

Un cuadro muy útil del actual debate "metodológico" de la ciencia penal, con atención especial a la situación alemana y española, en SILVA SÁNCHEZ, Aproximación al derecho penal contemporáneo, Bosch, Barcelona, 1992.

${ }^{40}$ Por ejemplo, HASSEMER, Über die Berücksichtigung von Folgen, cit. En este trabajo, además, junto a la actualidad de la orientación a las consecuencias en la política criminal, en la legislación y en la construcción teórica (ibidem, 502 ss.), se ponen de manifiesto, sobre todo, los riesgos y los límites negativos que tiene la orientación a las consecuencias en la aplicación judicial (ibidem, 516 ss.); ID., Prävention im Strafrecht, cit., especialmente, 260 s., donde se distingue entre consecuencias "internas" y "externas" al sistema, aclarando que únicamente éstas últimas permiten una utilización provechosa del concepto de "consecuencias"; por el 
Donini - La relación entre Derecho Penal y Política: método democrático y método científico

Especialmente quien ha hablado de orientación a las consecuencias ha pretendido plantear una objeción metodológica que quisiera retomar aquí y hacer mía añadiendo algunas otras observaciones.

Hassemer ha observado en diversas ocasiones que la dogmática orientada en sentido político-criminal a las consecuencias adolece de una auténtica orientación a las consecuencias, esto es, falta sensibilidad respecto al banco de pruebas que constituye el saber empírico, la verificación ${ }^{41}$.

Si individualizamos "rationes", "fines", o bien, "funciones" de forma puramente idealista, teórico-abstracta o ideológica, se opera con valores, con fines, con el "deber ser" pero no se verifican nunca las auténticas funciones preventivas a la luz de investigaciones empíricas. Esta "prevención", si no está sujeta a verificación y a falsabilidad, no es más que un puro disfraz ideológico, una organización intelectual de lo que existe para que sea culturalmente aceptable.

Esta misma forma de proceder puede encontrarse en la Corte Constitucional italiana que hace un uso argumentativo de principios (por ejemplo, el de extrema ratio, el de la función reeducativa de la pena) sin ningún instrumento o prueba empírica. Se supone que la norma penal "tiene" que motivar, "tiene" que tener una función de prevención general, "tiene" que ser taxativa, "tiene" que prever una pena que tienda a la reeducación/resocialización, etc.: de lo que se deducen algunas consecuencias normativas, que inciden en los razonamientos del intérprete y del juez. En esto consiste la «funcionalización» de conceptos o su racionalidad a fines. Entendámonos: todo esto es mucho mejor que una cultura retribucionista-axiológica que sólo se preocupe de la reafirmación de la vigencia de las normas penales, de la compensación de culpas o de la Gesinnung, o bien, que se oriente a la educación disciplinaria del ciudadano que haya transgredido las reglas de su "papel" de garante de alguna función de riesgo.

Y, sin embargo, también esa cultura se orienta a las consecuencias sólo en apariencia. La argumentación dogmática se orienta a "consecuencias" que son siempre normativas. Son consecuencias internas al sistema de la propia dogmática que dice estar "orientada a las consecuencias". No son consecuencias "reales", y no parten de premisas "reales", son autopoiéticas. Basta con corregir el objetivo al que tiende el derecho penal y sostener que éste pretende estabilizar el consenso sobre los valores fundamentales de la sociedad, y nos encontraremos de nuevo inmersos en el idealismo penal, y no en el realismo o en el método experimental.

Esta cultura idealista tiene que ser necesariamente gestionada por técnicos cualificados y autorizados: es una gestión tecnocrática y de élite. Pero sus intérpretes carecen, por definición, de la posibilidad de "control crítico" de los datos reales, de la posibilidad de verificación. Su método no es falseable. El único control no se establece

contrario, si las consecuencias son únicamente internas al sistema, nos movemos en una dimensión completamente normativa.

41 Cfr. por ejemplo, HASSEMER, Strafziele im sozialwissenschaftlich orientierten Strafrecht, en HASSEMER/LÜDERSSEN/NAUCKE, Fortschritte im Strafrecht durch die Sozialwissenschaften, cit., 57 ss.; ID., Prävention im Strafrecht, cit., 257 ss., 260 s.; ID., Variationen der positiven Generalprävention, in SCHÜNEMANN/VON HIRSCH/JAREBORG (Hrsg.), Positive Generalprävention (Uppsala-Symposium 1996), Müller Verlag, Heidelberg, 1998, 47 s. Antes aún, cfr. CALLIESS, Theorie der Strafe im demokratischen und sozialen Rechtsstaat, Fischer, Frankfurt a.M., 1974, 122 ss., 206 ss. 
REJ - Revista de Estudios de la Justicia - No 4 - Año 2004

respecto a los efectos reales, sino respecto a la racionalidad de valores y de fines: el paradigma normativo integral impide que el juez del derecho (y de los valores) se ensucie aquí las manos con la realidad ${ }^{42}$.

Tampoco la experiencia alemana, atinente a la relación entre "ciencia penal" y su "política criminal", puede, en cierta medida, sustraerse a la misma crítica. Por ejemplo: el penalista italiano, en mi opinión, no ha comprendido realmente si las diversas "soluciones" a los casos presentes en los manuales alemanes de Jescheck (ahora Jescheck/Weigend), Roxin o Jakobs dependen de sus premisas teóricas o de cualquier otra cosa. Mas aún si tenemos en cuenta que muchas veces esas premisas teóricas conducen a soluciones idénticas o análogas, aunque se haya argumentado de forma diversa (¡es una diferencia de Begründung, no de "consecuencias"!).

Se tiene la sensación de que nos movemos siempre en una dimensión "idealista" en la que el derecho es un instrumento autopoiético, no un instrumento que se modifica en función de sus consecuencias aplicativas reales.

Pues bien, considero que pertenece al "método democrático", además de al "método de la ciencia", una apertura a la realidad mayor, un mayor compromiso de sus argumentos y soluciones con el output de los efectos que de ellos se derivan. Es decir, una orientación "real" a las consecuencias. De lo contrario seguiría siendo cierto que el derecho penal conserva el papel (que es importantísimo, sin duda) de aparato de control social y de estabilización de las expectativas de seguridad y de justicia. Sería entonces, únicamente, un papel de ideología pública: de política, por tanto, más que de ciencia ${ }^{43}$.

Naturalmente, la democracia penal del consenso político podría centrarse en impulsos emotivos y en el miedo de las víctimas potenciales, para eludir cualquier clase de verificación empírica, buscando así legitimación al uso irracional de los instrumentos punitivos (supra, \1.0). Es evidente que cuando reclamo un método democrático correcto con relación a la ciencia y a la política penales, no me refiero a la regla puramente procesal de la mayoría, sino a la información de la mayoría.

\subsection{E1 juego de los roles: ciencia académica y judicatura (en Italia) frente al legislador: "Die Reform sind wir"?}

Para un penalista italiano tiene mucho interés la lectura de las consideraciones realizadas recientemente por Gunther Arzt sobre el sentimiento de "identidad" de la ciencia penal alemana (académica) con respecto a la legislación penal del siglo XX. El penalista alemán afirma orgullosamente: "Die Reform sind wir"44, refiriéndose al hecho de que, por un lado, la legislación penal no ha podido prescindir de la aportación de la ciencia a lo largo de todo el siglo XX, y, por otro no puede prescindir, aunque a veces se

\footnotetext{
42 Para una oportuna ilustración del „nivel descriptivo“ de las funciones reales del derecho penal, SILVA SÁNCHEZ, Aproximación, cit., 298 ss.

43 Esta idea puede recordar las críticas tradicionales, de raíz marxista, a la teoría del delito como forma de ideología. Aquellas objeciones, por otro lado, conducían a los teóricos marxistas no ya a la relativización, sino más bien a la eliminación de toda diferencia entre derecho y política. Algo que excede completamente de la posición que se mantiene aquí (más ampliamente, sobre el tema, DONINI, Dogmatica penale e politica criminale a orientamento costituzionalistico, cit., especialmente- 39-44, 56-63).

44 ARZT, Wissenschaftbedarf nach dem 6. StrRG, cit., 757 ss.
} 
Donini - La relación entre Derecho Penal y Política: método democrático y método científico

olvide de ello. Es cierto. Este conocimiento también podría explicar cómo es posible que la ciencia penal alemana se haya "enamorado" de esa forma de la sociedad punitiva. Ha sido así porque siente que, en parte, es un producto suyo, porque ha tejido su ideología, realizando un esfuerzo inmenso para explicarla o hacerla aceptable.

Si nos fijamos en la experiencia de otros países, no encontramos la misma relación entre academia y legislación, ni la misma sensibilidad. Durante mucho tiempo la cultura académica en Italia, después de la experiencia del tecnicismo jurídico y del Código Rocco, se ha dirigido al Tribunal Constitucional, más que al Parlamento, para intentar realizar "sus" programas políticos de reforma. Es lo que ha conducido al desarrollo de una clase de estudiosos a menudo bastante crítica frente al legislador. Las buenas relaciones entre ellos dependen de en qué medida el Parlamento, o más a menudo, el Gobierno, ha sabido "implicar" a representantes de los docentes universitarios en los proyectos o en las comisiones de reforma. De todas formas, ya esté o no implicada la academia, a menudo queda infravalorada con respecto a los aportes de la judicatura: los juristas "ministeriales", los que componen los departamentos legislativos estables del Ministerio de Justicia, son, de hecho, magistrados, y como ya se ha recordado, es mucho más consistente la presión del poder judicial sobre el ejecutivo y el Parlamento, que la autoridad de una clase académica que hoy en día está demasiado ocupada en la actividad profesional de la abogacía y que, además está, en parte, dividida en escuelas "regionales" en las que los protagonismos individuales o las rivalidades relativas al poder académico-de oposición, prevalecen sobre el diálogo científico que podría unir fuerzas en verdad representadas por varios talentos de nivel incluso internacional.

Además de todo lo que ya se ha dicho, si se considera que el Código Rocco de 1930 aún está vigente en su estructura básica, aunque sea el Código de la Italia republicana más que de la Italia fascista (ya que ha vivido bajo la República más de dos tercios de su existencia), y que parece que todavía es capaz de sobrevivir mucho tiempo, aunque sea con algún que otro retoque, se comprende perfectamente que la ciencia penal italiana no pueda tener el atrevimiento de proclamar: ¡"la reforma somos nosotros"!

Por todo ello, cuando se habla de la relación entre ciencia penal y política, no se debería olvidar la aportación de la sociología de roles nacionales, que explica más que muchas doctas monografías 45 . De otro lado, la política criminal "real" va por otros derroteros, distantes de las elaboraciones científicas. Cuando desde los Estados Unidos a la Inglaterra de Blair, y desde la Francia de Chirac a otros países mediterráneos sopla el viento de la "tolerancia cero", se hace evidente, para cualquier persona con sentido común, que no es precisamente la aportación de la ciencia jurídica la que explica la razón de ser de las reformas ${ }^{46}$.

De otra parte, la ciencia no puede continuar legitimando lo que ya existe si es sistemáticamente ignorada por el legislador, más aún cuando existe (como en Italia) una norma con rango de ley que, todavía hoy, prohíbe a los jueces citar obras doctrinales en

\footnotetext{
45 Para una reflexión muy instructiva de las relaciones entre ciencia penal y legislación en Italia, PALAZZO, Diritto penale, en Giuristi e legislatori. Pensiero giuridico e innovazione legislativa nel processo di produzione del diritto. Actas del Confreso de Florencia, 26-28 septiembre 1996, Giuffrè, Milán, 1997, 311 ss.

${ }^{46}$ Una visión intereseante del panorama internacional sobre estas tendencias en WACQUANT, Les prisons de la misère (1999), trad. it., Parola d'ordine: tolleranza zero. La trasformazione dello stato penale nella società neoliberale, Feltrinelli, Milán, 2000.
} 
los fundamentos de las sentencias ${ }^{47}$. Últimamente, se observa en Italia una mayor implicación de la clase académica en las iniciativas legislativas, pero en el contexto de una contribución "equilibrada" con la representación de la clase forense y la judicatura. Incluso esto, si se quiere, es un ejemplo de diplomacia penal, que no siempre de democracia.

Una característica destacada de la ciencia penal italiana de los últimos treinta años (que ya se daba en el siglo XIX) y que la distingue de otras similares ya sean europeas o no, es el método comparado. Esta característica la rehabilita claramente en un contexto internacional, junto con la vocación crítica, que me parece un poco más destacada de lo que pueda ser en otros contextos nacionales.

Aludiremos brevemente a este aspecto cuyo interés metodológico, desde mi punto de vista, debe integrar "sociológicamente" reflexiones de carácter más abstracto.

7.0. La dimensión internacional de los principios y la necesidad de que la comparación se convierta en "método de la dogmática" y no sea sólo una disciplina autónoma cuyos objetivos sean meramente cognoscitivos. Comparación y trabajo de équipe.

Una ciencia que sea sólo nacional ha sido siempre, desde mi punto de vista, una contradicción en sus propios términos, o mejor, la equivocación de un provincianismo nacionalista o de un iusracionalismo apodíctico para la exportación.

El sólo hecho de extender el horizonte del objeto de la ciencia penal más allá del derecho como norma, el sólo hecho de que el derecho como norma se conforme también con principios constitucionales, internacionales y derechos del hombre, que tienen una dimensión europea y extraeuropea, el sólo hecho de que la legislación nacional se "ocupe" progresivamente de normas cuya política real del derecho haya madurado en la Unión Europea y no en los Parlamentos nacionales, impone hoy a todo el mundo una apertura internacional y comparada a las ciencias jurídicas de los demás países. A consecuencia de ello se produce, necesariamente, una relativización de los puntos de vista autárquicos de las ciencias nacionales tradicionales ${ }^{48}$. Es por tanto una exigencia que ya no es exclusiva del círculo de escuelas que han tomado la decisión de trabajar con un método comparado, o bien una exigencia que se pueda circunscribir a aquéllos países que consideran que tienen "algo que aprender" de la experiencia que parece "más avanzada" o "interesante", de otros países.

Es cada vez más evidente que la "comparación" con una sola experiencia extranjera (que para muchos juristas italianos y españoles ha supuesto en el siglo XX un "monólogo" constante con los autores en lengua alemana), más que una comparación, corre el peligro de convertirse en una asimilación de otra cultura. Esto que puede desarrollar o ha desarrollado temporalmente en el pasado una función positiva, no puede constituirse en un 'método' que pueda repetirse indefinidamente; ya que no es ni un método de la ciencia, ni mucho menos de la democracia.

\footnotetext{
47 Se trata del art. 118. 3, de las Disposiciones Complementarias del Código Procesal Civil ("En todo caso se debe omitir la citación de cualquier autor jurídico")

48 En este sentido, vid. también PALAZZO/PAPA, Lezioni di diritto penale comparato, Giappichelli, Turín, 2000, 18 ss., y aquí (cap. I) una exposición crítica de las razones por las que se retoma el método comparado después del paréntesis del tecnicismo jurídico en Italia.
} 
La tradición italiana de la dogmática comparada (no sólo con Alemania, sino también con Francia, por ejemplo, y hoy en día también con los países de lengua española y de common law) se consolidó ya en el siglo XIX, y es, por tanto, claramente anterior a la internacionalización del derecho penal y prosiguió después en el siglo XX a pesar del (y sobre todo después del paréntesis) tecnicismo jurídico y de la primera época, todavía bastante 'autóctona' de la corriente constitucionalista. Con relación a los países de lengua española, baste sólo recordar en el siglo XX la obra monumental de Jiménez de Asúa y el manejo constante de la literatura italiana y alemana. Lo que se echa un poco en falta es una interacción recíproca, sobre todo por parte de la literatura alemana, que se ha dedicado casi exclusivamente a exportar sus productos, excepto por el hecho de haber ofrecido a través del Max Planck Institut de Friburgo una cosecha realmente significativa de trabajos e investigaciones de extensión realmente mundial. Una cosecha de materiales tan imponente como ignorada por parte de los estudios dogmáticos de la academia alemana ${ }^{49}$.

En cuando al modelo al que me refiero, no se trata de establecer una comparación únicamente como "ciencia autónoma", que se ocupe de describir institutos y legislaciones de otros Estados. La comparación tiene que verse hoy en día más que como método de la teoría del derecho o de la política del derecho como "método de la dogmática" (y se extiende, según el objeto de la investigación, a diversos países, no a ordenamientos-modelo); tiene que verse como un requisito de cientificidad de la propia ciencia penal dogmática50.

Un desarrollo maduro de este método implica la necesidad de que no se deje a la iniciativa y al conocimiento lingüístico de cada estudioso: el trabajo de équipe pasa así a ser un instrumento indispensable para una comparación de largo alcance ${ }^{51}$ y una contribución real a un diálogo que en el plano político exige condiciones de reciprocidad. De una parte, la comparación con un único país es asimilación, o bien, especialización de un estudioso en particular: pero nunca el trend generacional de toda una nación de investigadores. De otra parte, es patológico que este movimiento tenga lugar en una única dirección, esto es, que algunos países se comparen siempre con otros sin que exista un movimiento recíproco en sentido inverso. Nuestros países (España, Alemania e Italia) no pueden reducir el ámbito de la comparación a una autoreflexión que se enmarque en la tradición

49 Sobre este aislamiento nacionalista de la ciencia penal alemana, muy orientado a la exportación, y puesto en evidencia también en DONINI, voz Teoria, cit., 240 s., nota 83, se han producido en los últimos tiempos contribuciones de gran fuerza crítica: en especial, FLETCHER, Die dentsche Strafrechtswissenschaft im Spiegel der Rechtsvergleichung, en ESER/HASSEMER/BURCKHARDT, (Hrsg.), Die dentsche Strafrecbtswissenschaft vor der Jabrtausendwende, Beck, Munich, 2000, 239 ss.; SCHUBARTH, Binnenstrafrechtsdogmatik, und ihre Grenzen, en ZStW, 110, 1998, 827 ss.; cfr. también KÜHL, Europäisierung der Strafrechtswissenschaft, en ZStW, 109, 1997, 777 ss.; PERRON, Sind die nationalen Grenzen des Strafrechts überwindbar?, en ZStW, 109, 1997, 281 ss., 296 ss.; JUNG, Grundfragen der Strafrechtsvergleichung, en Juristische Schulung, 1998, 1 ss.

50 Sobre este punto, con ulteriores referencias, DONINI, voz Teoria del reato, cit., \$7. En este estudio he sostenido la necesidad de la comparación (que implique 'intercambios' lingüistico-conceptuales, y no simplemente la toma de conciencia de lo que es 'diverso') como método de la propia dogmática "nacional". Percibo una convergencia de puntos de vista, en relación a este aspecto, en la interesante intervención escrita para este Congreso por MILITELLO, Dogmatica penale e politica criminale in prospettiva europea (dactilografiado).

51 Ejemplares las investigaciones en équipe del Max Planck Institut für ausländisches und internationales Strafrecht und Kriminologie, de Friburgo en Brisgovia. Sobre este punto vid. también JESCHECK, Rechtsvergleichung im Max-Planck-Institut für ausländisches und internationales Strafrecbt im Freiburg i. Br., en ZStW, 79, 1967, 128 ss. Desde el punto de vista del método, estas investigaciones se han caracterizado fundamentalmente por la finalidad de conocer otros sistemas extranjeros, manteniendo un espléndido aislamiento respecto a los trabajos dogmáticos alemanes. Nunca se ha elaborado, o llevado a cabo una visión comparada "dentro" de las dogmáticas nacionales, aunque sea el "Lehrbuch" de Jescheck, hoy, Jescheck/Weigend, el que utilice más materiales extranjeros de todo el mundo. 
REJ - Revista de Estudios de la Justicia - No 4 - Año 2004

"dogmática" que nos es común. Por eso considero que es importantísima una apertura a los sistemas de common law ${ }^{52}$.

Se abriría así un tema que merecería por sí mismo muchas reflexiones a las que está más acostumbrada la ciencia comparada de matriz civilista, un tema que concierne al objeto, método y fines de la comparación ${ }^{53}$. Pero no quisiera entrar ahora aquí para no hacer pesado mi discurso, ya que trato de expresar únicamente un concepto que para mí es más importante que cualquier otro. Y éste sería la necesidad de que la comparación no sea únicamente una disciplina autónoma que "conoce" lo que es distinto y lo "describe" con categorías comprensibles para el lector, sino que sea también un método de contraste y diálogo discursivo (con un secundum comparationis que pueda ir cambiando en la medida en que lo haga el argumento y el objeto, y con un tertium comparationis que funcione como "medium" entre el primum y el secundum comparationis) común al mismo milieu cultural, que no sea un método individual o específico de algún pionero o grupo de alguna nación económicamente (más) "débil"; de lo contrario, algunos importan siempre y otros exportan siempre.

\footnotetext{
${ }^{5} \mathrm{Me}$ permito disentir, en este punto, de lo que ha afirmado Silva Sánchez en la hermosa intervención escrita con ocasión de este Congreso (SILVA SÁNCHEZ, Retos cientificos y retos politicos de la ciencia del Derecho penal, p. 10 ss. del dactilografiado), donde manifiesta su excepticismo sobre la posibilidad de una comparación útil con los sistemas de common law, debido a la excesiva diversidad cultural y a la ausencia de una teoría del delito. Una contribución reciente y ejemplar que prueba la utilidad de la comparación con estos países, una utilidad que va más allá de las pasiones y de los vicios de la sistemática penal constructiva, puede leerse en CADOPPI, Il valore del precedente, cit., precisamente en relación a la pregunta que se plantea Silva Sánchez (ibidem, p. 12-13) sobre la mayor "seguridad y precisión" de un sistema de reglas organizado según una teoría, respecto de un sistema más casuístico. La respuesta del trabajo de Cadoppi, en este aspecto, que se atiene a una visión de la law in action, y no "in the books", va en un sentido exactamente opuesto al de Silva. Sin querer radicalizar ahora el juicio, sí quisiera señalar que es muy provechoso profundizar en otros sistemas, ya que de esta manera nos acostumbramos a relativizar, y con ello, a contextualizar mejor nuestro método tradicional. Si se aceptan las premisas que aquí se han acogido, es difícil postular que el sistema de origen alemán, pueda con seguridad constituir "el fundamento de la gramática occidental del Derecho penal" (tal y como afirma SILVA SÁNCHEZ, op.cit., p. 16 del dactilografiado). En mi opinión, tratándose de un lenguaje y de una gramática, muy articulados y complejos, es preciso valorar si no sería mejor, desde una estrategia inteligente y en el ámbito de un diálogo intercultural, partir de estructuras conceptuales y categorías más simples (por ejemplo, elemento objetivo/elemento subjetivo), o bien, de principios jurídico-constitucionales o de política criminal comunes. La cuestión política, de todas formas, me parece aún prioritaria respecto a la sistemática.

${ }^{53}$ Entre las investigaciones penales, recuerdo en particular (limitándome únicamente a las esenciales aunque es preciso destacar que además de éstas, no hay demasiado) además de Fletcher (nota 49), vid. LISZT, Das "ricbtige Recbt" in der Strafgesetzgebung, en ZStW, 26, 1906, 553 ss., también en ZWEIKERT/PUTTFARKEN (Hrsg.), Rechtsvergleichung, Wissenschaftliche Buchgesellschaft, Darmstadt, 1978, 57 ss.; JESCHECK, Entwicklung, Aufgaben und Methoden der Strafrechtsvergleichung, Mohr, Tübingen, 1955; ID., Die Bedeutung der Rechtsvergleichung für die Strafrechtsreform, en Fest. Bockelmann, Beck, Munich, 1979, 133 ss.; PEDRAZZI, L'apporto della comparazione alle discipline penalistiche, en SACCO (a cargo de), L'apporto della comparazione alla scienza giuridica, Giuffrè, Milán, 1980, 169 ss.; NUVOLONE, Il diritto comparato quale mezzo di ricerca nell'ambito della politica criminale, en Indice pen., 1980, 1 ss.; JESCHECK/KAISER (Hrsg.), Die Vergleichung als Methode der Strafrechtswissenschaft und der Kriminologie, Duncker \& Humblot, Berlín, 1980; J. HALL, Comparative Criminal Law as Basic Research (1978), en ID., Law, Social Science and Criminal Theory, Fred B. Rothman \& CO., Littelton, Colorado, 1982, 153 ss.; FLETCHER, Criminal Theory as an International Discipline, en ESER/FLETCHER(Hrsg.), Rechtfertigung und Entschuldigung. Rechtsvergleichende Perspektiven, II, Eigenverlag Max Planck Institut für ausländisches und internationales Strafrecht, Freiburg i.Br., 1988, 1595 ss.; ID., Comparative Law as Subversive Discipline, en Am. Journal of Comparative Law, 1998, 683, ss.; PRADEL, Dorit pénal comparé, Dalloz, Paris, 1995; ESER, The Importance of Comparative Legal Research for the Development of Criminal Sciences, en BLAINPAIN (ed.), Law in Motion, Kluwer, La Haya, 1997, 492 ss., en alemán ID., Funktionen, Methoden und Grenzen der Strafrechtsvergelichung, en Fest. Kaiser, Duncker \& Humblot, Berlín, 1998, Bd. II, 1499 ss.; TULKENS, Les systèmes de justice pénale comparée: de la diversité au rapprochement. Les politiques pénales et le comparativisme, en
} Nouvelles études pénales, 1998, 63 ss., con referencias extensas al debate extrapenal. 
Donini - La relación entre Derecho Penal y Política: método democrático y método científico

En mi opinión, hoy en día, esta necesidad se está haciendo cada vez más acuciante en el contexto de la unificación jurídica europea, sobre todo en vista de los proyectos de un ius criminale (o poenale) commune europeo. Nunca, como en este momento histórico, se ha advertido la preocupación relativa a que se impongan autoritariamente desde «arriba» las denominadas armonizaciones o unificaciones jurídicas europeas ${ }^{54}$. A través de esta demanda se expresa una exigencia exquisitamente democrática en la relación entre derecho penal y política. No se trata de la búsqueda de un derecho penal 'perfecto', sino de la solución más democrática y científica a la necesidad «relativa» de un derecho penal común, partiendo del conocimiento de la existencia de diferencias e identidades insuperables.

Precisamente, la dimensión científica del saber penal puede contribuir a un diálogo efectivo, aunque sólo en la medida en que se base en la comparación como método de información empírico-normativa de los sistemas con los que se pretende dialogar. Sin ella se reproducirán los evidentes nacionalismos (una ciencia provincial que se impone con la razón de la fuerza) o nacionalismos enmascarados de iusracionalismo (una ciencia que tiende a imponerse con la fuerza de la razón, pero que en realidad quiere exportar también el producto de su propia racionalidad cultural y lingüística de carácter nacional, sin una auténtica voluntad dialogística o discursiva).

Sin embargo, actualmente tengo que confesar algo que hace tiempo no me habría atrevido a decir, o que quizás no habría tenido la lucidez de ver. Si hoy en día parece que ha llegado el momento de afirmar que la comparación es importante para el propio método dogmático del penalista, ello no depende del hecho de que la internacionalización de las relaciones haya permitido "descubrir" una verdad que existía o valía también antes, cuando imperaba el nacionalismo político. Viceversa, el hecho de que hoy en día se considere indispensable el diálogo entre culturas y sistemas diversos, se ha debido a una nueva política criminal europea e internacional; de ahí que haya surgido la necesidad (política, científica y práctica) del método comparado: por tanto, a la vista de la lectura y aplicación de nuevas fuentes jurídicas de matriz común o de destino común. El cambio en la política criminal nacional e internacional, es, en definitiva, el factor que ha desencadenado el nuevo método ${ }^{55}$.

\subsection{La dimensión política y "crítica" de los principios y la necesaria democratización de la ciencia. De la auctoritas institucional a la 'autoridad' basada en un saber verificable. Empirismo y método penal.}

El trabajo in team, aunque nunca pueda sustituir al estudio individual, hará inevitable un mayor diálogo entre los estudiosos, una mayor necesidad de transmitir con bases comunes, con conceptos ya experimentados, con lenguajes menos personalizados (la fascinación de la investigación individual); esto es, impondrá un estilo de pensamiento más

\footnotetext{
54 Expresa una preocupación de este tipo por ejemplo, HASSEMER, "Corpus Juris": Auf dem Weg zu einem europäischen Strafrecht?, en KritV, 1999, 133 ss., en relación a la primera edición del Corpus Juris. La segunda edición (DELMAS-MARTY/VERVAELE, The Implementation of the Corpus Juris in the Member States, vol. I, Intersentia, Antwerp-Groningen-Oxford, 2000; voll. 2 e 3, ibidem, 2001), se sustrae, desde mi punto de vista, a aquéllas críticas y reservas.

55 Con esta consideración se responde de forma clara e inmediata a las tentaciones ontologizantes; en este sentido un ejemplo claro en la producción más reciente se encuentra en, HIRSCH, Gibt es eine national unabhängige Strafrechtswissenschaft?, en Fest. Spendel, Walter de Gruyter, Berlín-New York, 1992, 43 ss.
} 
atento a datos cuantitativos, estadísticos, empíricos. En pocas palabras: abrirá el «método de la ciencia» a la discursividad del «método democrático» ${ }^{56}$, a sus procedimientos dialécticos en la construcción del 'sistema' como «obra colectiva» ${ }^{57}$.

No es que el consenso desinformado de la mayoría o una decisión "componedora" de un tribunal supremo (por ejemplo, el Tribunal Supremo en sesión plenaria) puedan imponerse a las adquisiciones científicas, sino que estas últimas no tienen ninguna dimensión útil, ningún auditorio, ningún significado práctico real, sin un destinatario del que es necesario obtener el consenso y del que se debe esperar y desear que realice un control crítico, ya que no es un súbdito que deba limitarse a obedecer preceptos basados en el principio de autoridad.

El anclaje de la ciencia en los "principios" (y no sólo en las categorías sistemáticas o en las normas ordinarias), exalta su vocación crítica, y no meramente «sistematizadora», amplía el horizonte de su objeto a la política criminal e, incluso, a la realidad que la política pretende gobernar. Ya no basta la autoridad del consenso de estudiosos o jueces que sean "expertos en normas" o "expertos en valores": su experiencia deberá medirse con conocimientos que puedan verificarse y ser controlados por laicos, ya que el derecho penal - sin renunciar a los valores - es un instrumento político, no de pura reafirmación de los propios valores, sino de un programa que mira a la propia realidad social y humana que se regula, al output extrasistémico de su intervención. El derecho penal tiene ciertamente una función simbólica (de reafirmación de valores en la conciencia colectiva). Es más, esta es su función más incontestable. Pero quien se resiste a ampliar el método (ya sea legislativo o interpretativo-aplicativo) impidiendo la entrada de mayores conocimientos empíricos y de output, es que está persuadido, ya desde el inicio, de que el derecho penal tiene que continuar desarrollando esencial o exclusivamente esa función simbólica.

Todo lo que aquí se ha sostenido -y es un aspecto muy delicado de toda esta problemática- exige configurar un papel distinto también para quien "aplica" el derecho, para una judicatura que debería consecuentemente ocuparse también de programas efectivos de fines y no sólo de programas condicionales ${ }^{58}$. La propia dimensión hermenéutica del derecho penal podría resultar profundamente revisada por la consecuente adopción de un tipo de perspectiva como ésta.

En el debate cultural contemporáneo los penalistas siempre llegan los últimos. La función de "última barrera" que desempeña el derecho penal, hace que sea poco idóneo para desempeñar un papel pionero.

\footnotetext{
56 Para un llamamiento a la importancia conjunta de comparación e investigaciones empíricas en el método de la codificación (nacional), MARINUCCI/DOLCINI, Note sul metodo della codificazione penale, en Riv.it.dir.proc.pen, $1992,410 \mathrm{~s}$

${ }^{57}$ Sobre esta imagen actual del sistema penal (y jurídico en general) me he detenido en DONINI, Teoria del reato. Una introdurione, cit., 10 s.; ID., voz Teoria, cit., 297.

58 Para una tematización de estos conceptos, aunque oponiéndose, por otro lado, a la orientación a las consecuencias en el ámbito de la dogmática, LUHMANN, Rechtssystem und Rechtsdogmatik, Kohlhammer, Stuttgart, 1974, tr. it., Sistema giuridico e dogmatica giuridica, Il Mulino, Bolonia, 1978, 61 ss., 78 ss., 96 ss.; una apertura significativa, por el contrario, en MENGONI, Ermeneutica e dogmatica giuridica, cit., 91 ss.
} 
Donini - La relación entre Derecho Penal y Política: método democrático y método científico

$\mathrm{Y}$, sin embargo, es justamente por este motivo por el que el derecho penal es realmente el auténtico banco de pruebas para realizar teorizaciones sobre el derecho "en general", sobre la interpretación "en general", sobre el papel de la judicatura "en general", etc. que provienen a menudo de áreas filosóficas, o bien de derecho privado o constitucional.

Quien cultiva nuestra materia desempeña el papel político de prueba de la bondad o no de tantas construcciones generales sobre el derecho tout court. si la orientación a las consecuencias, el significado del precedente judicial, el papel de la tópica y de la jurisprudencia como fuente de derecho, la relación entre principios y reglas, la importancia de la lógica "fuzzy", el valor constitutivo de la comparación para el método dogmático, la apertura a las ciencias sociales y al output de las soluciones teóricas, se adaptan también al derecho penal, estas teorizaciones tendrán realmente el significado paradigmático general que ambicionan. Nos espera una gran tarea, y no sólo la mera y preconcebida "conservación".

En esta tarea es imprescindible la necesidad de interacción entre dimensiones metodológicas diversas, individualizadoras y generalizadoras (supra, \3.0). Pero el reto hacia una apertura y un incremento de saber empírico controlable, pasa siempre a través de su entrada prioritaria en fase legislativa, y en su verificación a la luz de la dimensión decisoria e institucional del derecho: sin una legislación basada en el empirismo, el papel de la ciencia penal podrá ser crítico, pero poco "explicativo" de programas de fines sin consecuencias, ya que el proyecto legislativo ni siquiera las ha imaginado nunca o las ha llegado a conocer.

Si se comparten estas premisas, no sé si todos nosotros podremos continuar investigando como hemos hecho hasta ahora. Ni siquiera sé si es del todo correcto lo que propongo. Si lo fuese, probablemente habríamos señalado algunos puntos de partida no sólo en la dirección de la ciencia, sino también en la de la democracia. 